Acta psychother. 1963;11(Suppl.):1-4

\title{
Contents, Vol. 11, 1963
}

\section{Index}

Phyloanalysis (Burrow) - Its Historical and Philosophical Implications

By W. Riese, Glen Allen, Va.

The Substance and Sources of Burrow's Thesis

The Basic Theme: Man’s Wholeness is Man's Wholesomeness

A Socio-Physiological Conception of Man

The Threefold Passage from Man's Original to His Actual Condition

Civilization and Disease

23

Summary

33

Zusammenfassung

Resume

34

References

34

Reflections on Group• or Phylo-Analysis

By H. Syz, Westport, Conn.

Introduction 37

I. Development of Group-Analysis

II. Conceptual Aspects

Organismic-Configurational Principles

Human Nature and the "Social Neurosis"

V. Relation to Other Formulations

55

VI. Psychophysiological Processes and Proprioceptive Experimentation ... 73

Summary

Zusammenfassung

Resume

79

References 